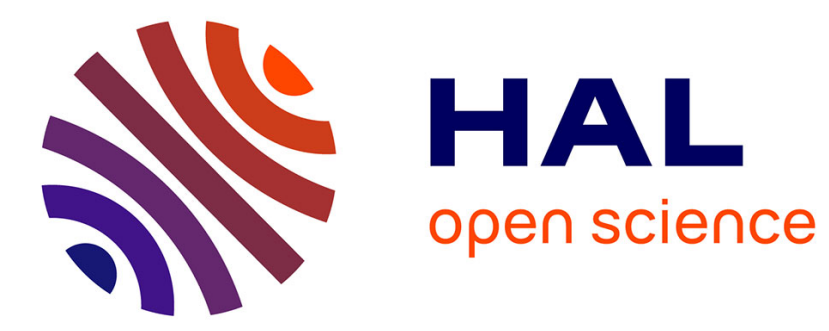

\title{
Multiscale study and kinetic modeling of PDCPD thermal oxidation
}

\author{
Jing Huang, Emmanuel Richaud, Pierre-Yves Le Gac, Adelina David, Renata \\ Drozdzak, Recher Gilles
}

\section{- To cite this version:}

Jing Huang, Emmanuel Richaud, Pierre-Yves Le Gac, Adelina David, Renata Drozdzak, et al.. Multiscale study and kinetic modeling of PDCPD thermal oxidation. Service Life Prediction of Polymers and Coatings Enhanced Methods, Elsevier, pp.103-116, 2020, 10.1016/B978-0-12-818367-0.00007-2 . hal-02591838

\section{HAL Id: hal-02591838 \\ https://hal.science/hal-02591838}

Submitted on 15 May 2020

HAL is a multi-disciplinary open access archive for the deposit and dissemination of scientific research documents, whether they are published or not. The documents may come from teaching and research institutions in France or abroad, or from public or private research centers.
L'archive ouverte pluridisciplinaire HAL, est destinée au dépôt et à la diffusion de documents scientifiques de niveau recherche, publiés ou non, émanant des établissements d'enseignement et de recherche français ou étrangers, des laboratoires publics ou privés. 


\section{Multiscale study and kinetic modeling of PDCPD thermal oxidation}

Jing Huanga, Emmanuel Richauda, Pierre-Yves Le Gac ${ }^{b}$, Adelina David ${ }^{b}$, Renata Drozdzakc, Gilles Recher ${ }^{c}$

aLABORATOIRE PIMM, ENSAM, CNRS, CNAM, HESAM, 151 BOULEVARD DE L'HÔPITAL, PARIS, FRANCE; 'IFREMER, SERVICE MATÉRIAUX ET STRUCTURES, CENTRE DE BREST BPTO,

PLOUZANÉ, FRANCE; 'TELENE SAS, 2, RUE MARIE CURIE, BONDUES, FRANCE

\section{Introduction}

PDCPD is one of the youngest members of the thermoset family. It was developed in the laboratories of BFGoodrich and Hercules and is now used on large scale in a variety of applications. Compared to other thermosets, PDCPD has excellent impact performance, superior chemical resistance, and very low water absorption $(0.09 \%$ weight increase after $24 \mathrm{~h}$ in water). PDCPD areas of applications include large to very large parts, typically in small to medium series, possibly used in hostile environments, and where design freedom is favored. Some examples include body panels for agricultural and construction equipment, trucks and buses where PDCPD brings high impact resistance even at $-40^{\circ} \mathrm{C}$, and a high heat deflection temperature (typically $>100^{\circ} \mathrm{C}$ ). PDCPD is obtained through Ring Opening Metathesis Polymerisation (ROMP) of the DCPD monomer. 'ROMP reaction' is a metal carbene catalyzed reaction using strained cyclic olefins to produce a wide range of polymers. The driving force is the relief of ring strain.

Today's commercial DCPD resin formulations based on Molybdenum and Tungsten are processed using Reaction Injection Moulding (RIM). In the RIM process two or three monomer streams are brought together in a mixing head and then injected in the mould where the polymerisation takes place. The RIM process is especially suitable to produce large plastic parts. The formulations based on Ruthenium catalysts are no longer limited to RIM but can be used in a variety of thermoset process such as resin infusion and RTM. The robust nature of the Ruthenium catalysts allows using reinforcements such as glass and mineral fibers, foaming agents, and other types of fillers. It has been demonstrated that PDCPD glass fibers composites exhibit superior fatigue resistance and damage tolerance without compromising on the ultimate strength. 
PDCPD has excellent impact performance, superior chemical resistance, very low water absorption, very low dielectric constant, excellent thermal stability, and intrinsic fracturetoughness properties that are desirable for a variety of applications. The high density of carbon-carbon double bonds in the polymer backbone makes polydicyclopentadiene susceptible to oxidation. The oxidized layer which is formed spontaneously on PDCPD thick parts allows efficient part painting by using conventional paints.

The oxidation process, however, can also lead to the oxidative polymer damage which might have an important influence on overall mechanical properties. Polymer aging due to oxidation is considered as irreversible. Therefore, it is very important to understand the oxidation mechanism of PDCPD polymer and find a method to increase its oxidative stability.

\section{Mechanical failure in PDCPD submitted to thermal oxidation}

When PDCPD undergoes oxidation, large changes of the mechanical behavior occur as shown in Fig. 7.1. This figure plots tensile curves of $3 \mathrm{~mm}$ thick PDCPD for several aging duration in oven at $140^{\circ} \mathrm{C}$. A large decrease in elongation at break clearly appears whereas the modulus is almost constant during oxidation. This large decrease in fracture properties is related to chemical modification of the network during the degradation. In fact, during polymer oxidation both chain scission and crosslinking occur. For PDCPD, a large crosslinking process occurs due to the presence of double bonds in the polymer backbone. This crosslinking process can be highlighted considering the modulus in the rubbery state that is directly proportional to the crosslink density in the material. For example, Fig. 7.2 shows DMA results for several aging durations in seawater at $90^{\circ} \mathrm{C}$ where degradation processes are similar as in air. A clear increase in the rubbery plateau is observed that clearly indicates a large increase in crosslink density during oxidation.

Previous results obtained with $2 \mathrm{~mm}$ thick samples revealed that the oxidation process is limited by oxygen diffusion and a degradation profile exists through sample [1] (as it

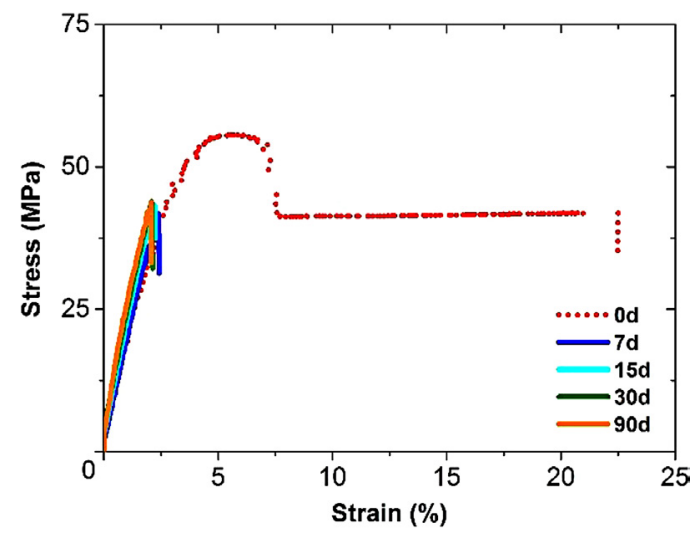

FIGURE 7.1 Tensile behavior of $2 \mathrm{~mm}$ thick commercial PDCPD after oxidation after several aging time at $140^{\circ} \mathrm{C}$. 


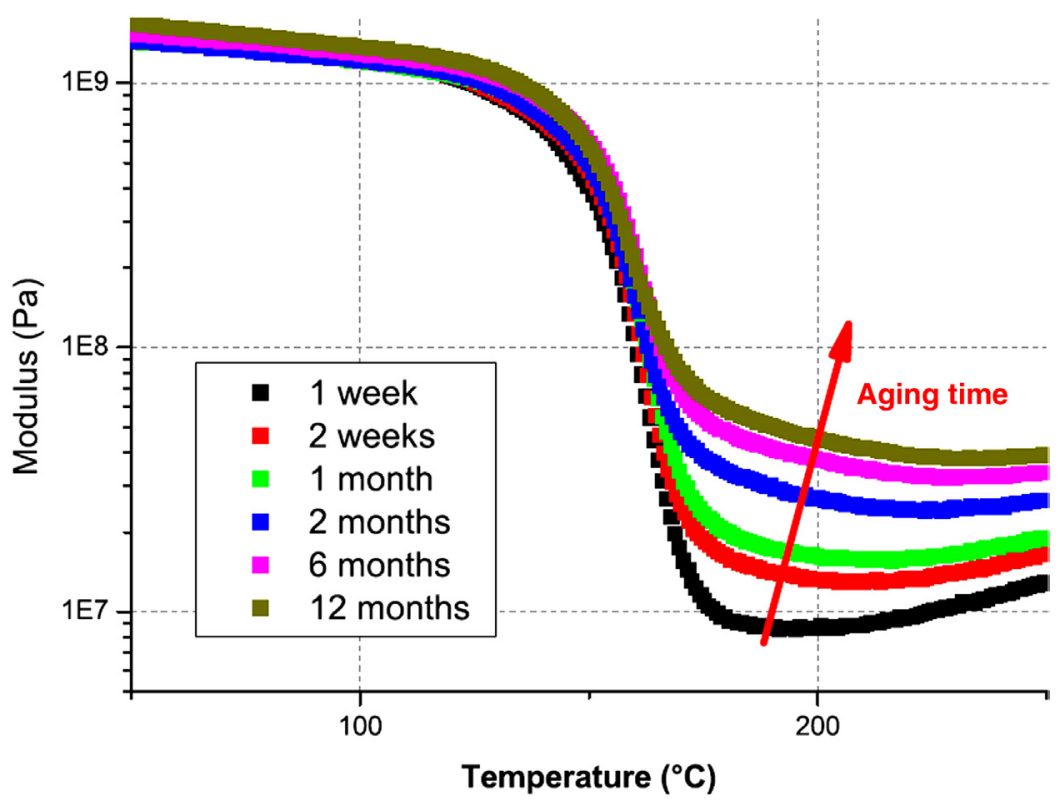

FIGURE 7.2 Change in modulus with temperature for different aging times in seawater at $90^{\circ} \mathrm{C}$ [1].

will be developed in the next section). In order to understand mechanical changes during oxidation process of the PDCPD, thin films (i.e., $60 \mu \mathrm{m}$ thick samples) were aged at $80^{\circ} \mathrm{C}$ in oven. In these conditions, oxidation is homogeneous through sample thickness. Changes in Young's modulus and maximal stress during oxidation are plotted in Fig. 7.3.

Both modulus and maximal stress increase during oxidation, which can be related to the crosslinking process induced by degradation. First, the modulus in glassy state is related to cohesion and segmental mobility [2] and its changes will be studied in future work. Then let us consider the maximal stress increase. During crosslinking induced by
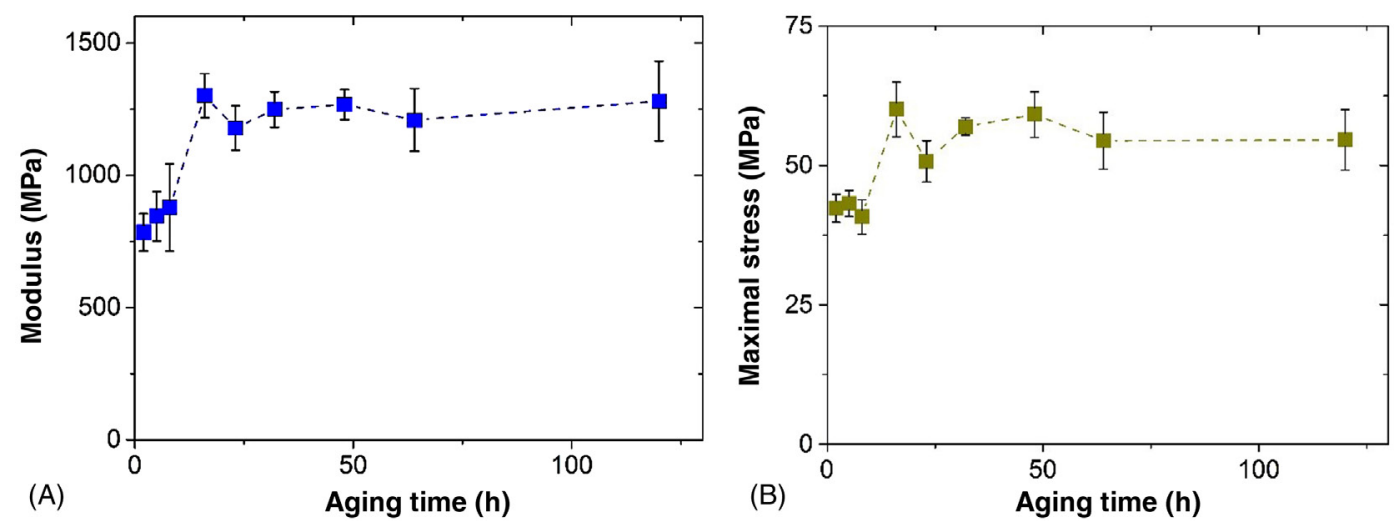

FIGURE 7.3 Changes in Young modulus (A) and maximal stress (B) as function of aging time using $60 \mu \mathrm{m}$ thick films aged at $80^{\circ} \mathrm{C}$. 
oxidation, an increase of $\mathrm{T}_{\mathrm{g}}$ is expected. In fact, according to Eyring's equation based on free volume theory at a given strain rate it is possible to show that stress at yield is directly related to $\mathrm{T}_{\mathrm{g}}$ according to:

$$
\sigma_{\mathrm{y}}=\mathrm{C} \cdot\left(\mathrm{T}_{\mathrm{g}}-T\right)
$$

where $\sigma_{\mathrm{y}}$ is the stress at yield, $\mathrm{C}$ is a constant that depends on strain rate, $\mathrm{T}_{\mathrm{g}}$ is the glass temperature transition and $\mathrm{T}$ the absolute temperature.

As a conclusion it appears that oxidation leads to a large increase in crosslink density. In terms of mechanical behavior, it leads to a drastic reduction of the elongation at break, a slight increase in Young modulus related to cohesive energy as well as an improvement in maximal stress. This latter increase can be attributed to an increase in $\mathrm{T}_{\mathrm{g}}$ that will be characterized in the future.

\section{Molecular changes in oxidized PDCPD}

\subsection{Estimation of thickness of oxidized layer}

The effect of sample thickness has been studied by TGA. Samples with different thicknesses were aged at 120 and $150^{\circ} \mathrm{C}$ under 1 bar $\mathrm{O}_{2}$ so as to determine the maximal thickness below which oxidation is not controlled by oxygen diffusion. TGA curves are presented in Fig. 7.4. At $150^{\circ} \mathrm{C}$, the rate of mass uptake reaches rapidly its maximal value $\left(\mathrm{r}_{\mathrm{m}}\right)$. The maximal rate seems almost constant for samples having a thickness lower than about $20 \mu \mathrm{m}$ (Fig. 7.4) which corresponds to twice the thickness of oxidized layer (TOL). Since it is well established that the TOL decreases with temperature $[3,4]$, its value will, hence, be assumed higher than $10 \mu \mathrm{m}$ for temperatures lower than $150^{\circ} \mathrm{C}$ so that oxidation will be studied for samples about $10 \mu \mathrm{m}$ thick.

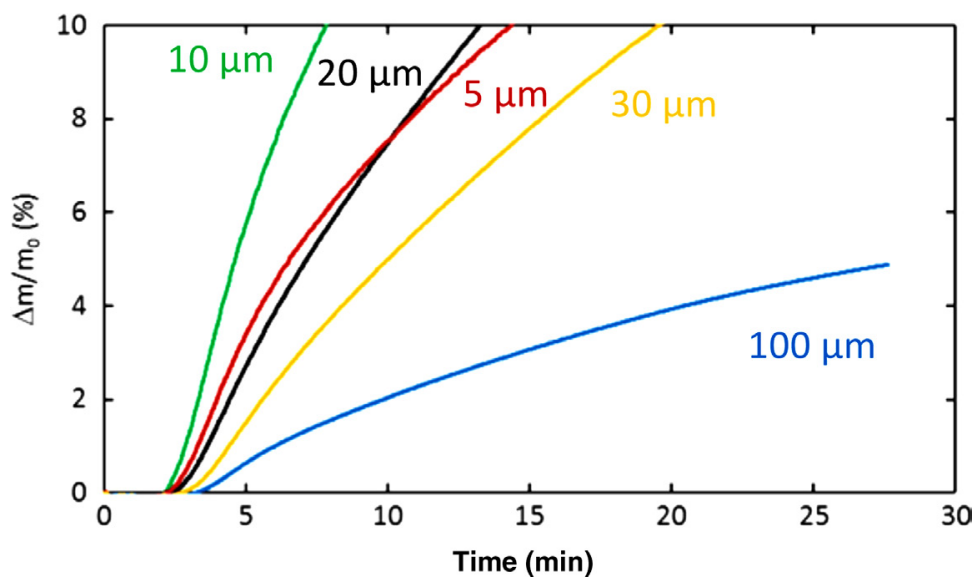

FIGURE 7.4 Gravimetric curves for purified PDCPD films and aged at $150^{\circ} \mathrm{C}$ under 1 bar $\mathrm{O}_{2}$ [5]. 


\subsection{Detection and quantification of hydroperoxides}

Infrared spectra shows a growth of a hydrogen bonded hydroxyl band at ca. $3400 \mathrm{~cm}^{-1}$ (Fig. 7.5A). This broad band consists of various species corresponding to hydroxyl groups being either hydroperoxides, alcohols or carboxylic acids, all of which being reported to be oxidation products in other hydrocarbon polymers [6]. It is, however, difficult to really distinguish all these species.

However, hydroperoxides (being the key species of the oxidation mechanisms) can also be detected and quantified by other chemical or thermal methods [7]. The following DSC procedure was used for the titration of hydroperoxides:

- equilibrate at room temperature

- heating to $300^{\circ} \mathrm{C}$ under nitrogen at a $10^{\circ} \mathrm{C} \mathrm{min}^{-1}$ rate

The DSC traces of oxidized samples reveal the growth of an exotherm centered at about $150^{\circ} \mathrm{C}$ which disappears upon treatment by sulfur dioxide (Fig. 7.6A). The same disappearance occurs after the second cycle of the same DSC procedure. That means that this
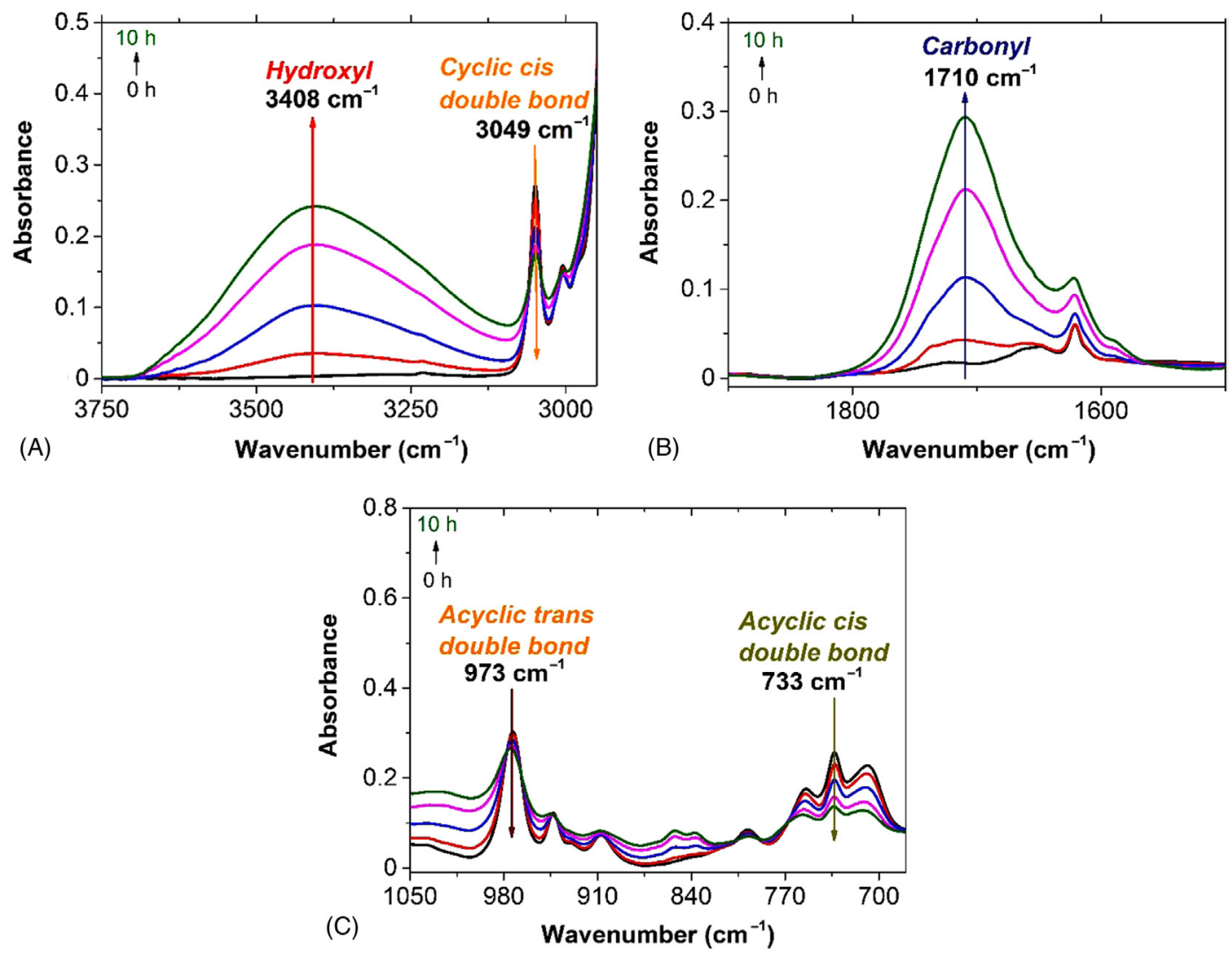

FIGURE 7.5 Changes of FTIR spectra of purified PDCPD exposed at $50^{\circ} \mathrm{C}$ under air in hydroxyl (A), carbonyl (B), and double bonds (C). 

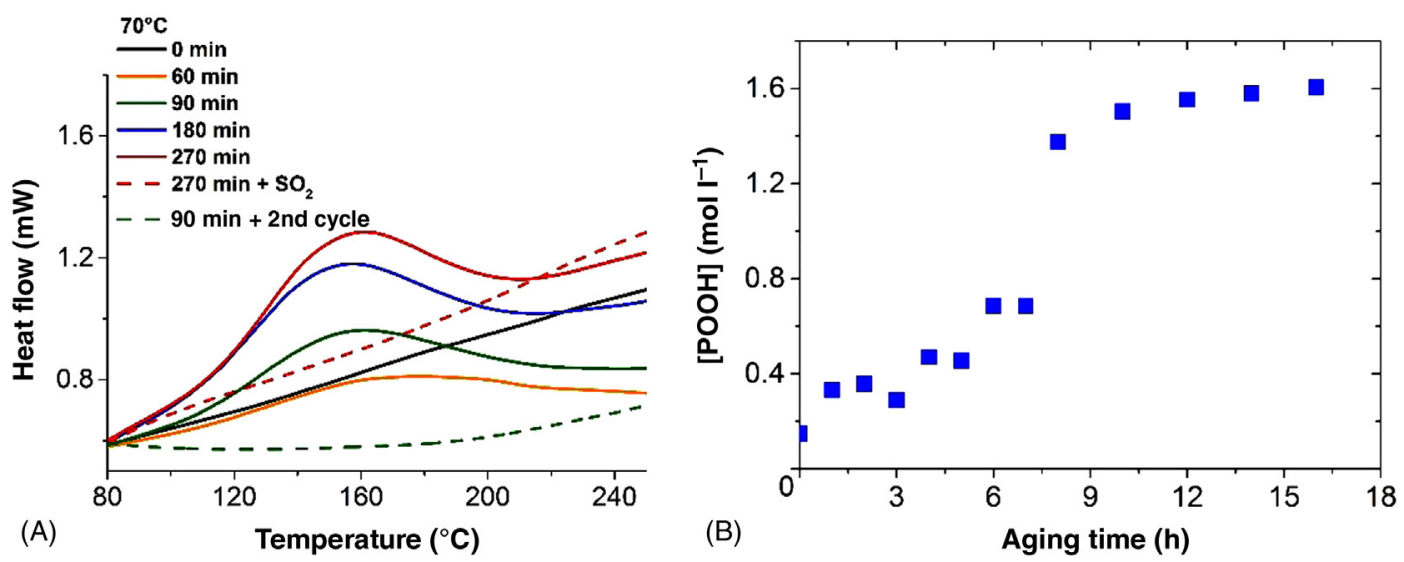

FIGURE 7.6 DSC thermograms before (full line) and after (dashed line) $\mathrm{SO}_{2}$ treatment for purified.

titration of hydroperoxides is irreversible. This exotherm is hence attributed to the decomposition of hydroperoxides (POOH) formed during the propagation step (Scheme 7.1).

PDCPD exposed at $70^{\circ} \mathrm{C}$ under air (1). Changes in hydroperoxides for PDCPD exposed at $50^{\circ} \mathrm{C}$ under air (2).

Several kinds of hydroperoxides can be formed (Fig. 7.7).

$\mathrm{POOH}$ concentration was calculated (Fig. 7.6B) using a molar enthalpy $\left(440 \mathrm{~kJ} \mathrm{~mol}^{-1}\right)$ given by our previous study [8]. At $50^{\circ} \mathrm{C}$, it is observed to increase rapidly in the earliest exposure time to reach a value of about $1.5 \mathrm{~mol} \mathrm{l}^{-1}$ after $10 \mathrm{~h}$ of exposure and then to reach a plateau. Hydroperoxides are an intermediate species of oxidation process and decompose later to generate stable products as presented below.

\subsection{Carbonyl build-up}

Fig. 7.5B displays a complex carbonyl band in the $1650-1750 \mathrm{~cm}^{-1}$ region with a maximum centered at ca. $1710 \mathrm{~cm}^{-1}$ corresponding to the aldehydes or ketones. There are at least three kinds of reactions likely to explain their origin:

(1) By initiation process (i.e., uni- or bimolecular decomposition of peroxides), for example as shown in Scheme 7.2.

NB : hydroperoxides decomposition by uni- or bimolecular process generate the same kind of alkoxy radical :
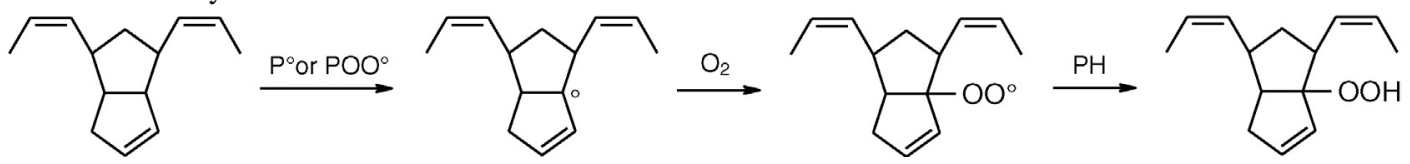

SCHEME 7.1 Propagation step in PDCPD.
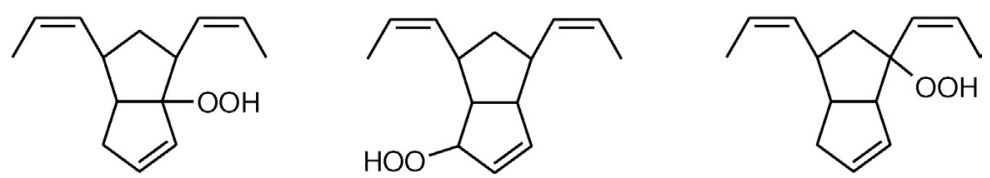

FIGURE 7.7 Possible structures of hydroperoxides in PDCDP. 


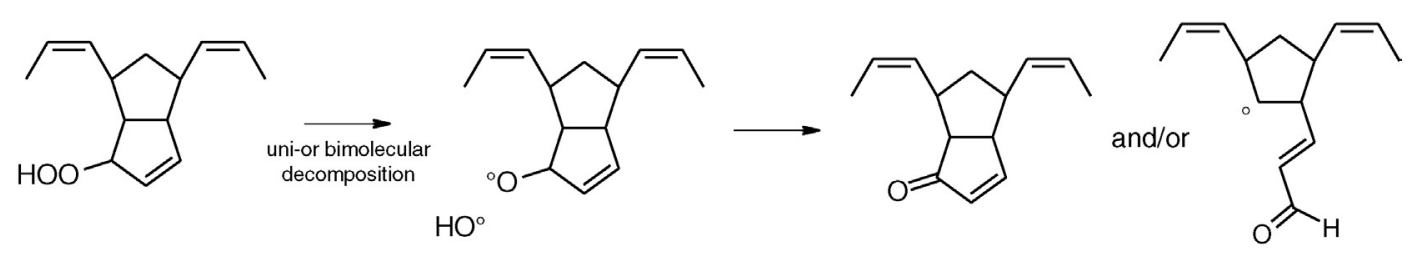

(A)

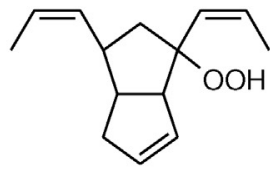

uni-or bimolecular $\mathrm{O}$ decomposition
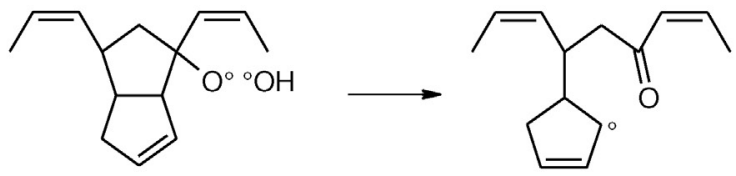

(B)

SCHEME 7.2 Formation of carbonyls from hydroperoxides decomposition.

$\mathrm{POOH} \rightarrow \mathrm{PO}^{\circ}+{ }^{\circ} \mathrm{OH}$

$\mathrm{POOH}+\mathrm{POOH} \rightarrow \mathrm{POO}^{\circ}+\mathrm{PO}^{\circ}+\mathrm{H}_{2} \mathrm{O}$

And then: $\mathrm{PO}^{\circ} \rightarrow \gamma_{1} \mathrm{P}=\mathrm{O}+\left(1-\gamma_{1}\right) \mathrm{POH}, \mathrm{P}=\mathrm{O}$ being a carbonyl and $\mathrm{POH}$ and alcohol.

(2) By the decomposition of dialkylperoxides generated by the termination process between an alkyl $\left(\mathrm{P}^{\circ}\right)$ and a peroxyl $\left(\mathrm{POO}^{\circ}\right)($ Scheme $7.3 \mathrm{~A})$ :

(3) By the decomposition of tetroxides generated by termination process between two peroxy $\left(\mathrm{POO}^{\circ}\right)$ radicals (Scheme 7.3B) [9].

It must be mentioned that POOP and POOOOP decomposition generate a pair of alkoxy radicals in each case, so that the mechanisms can be considered as close. However, the kinetics are not priori because POOP and POOOOP stabilities are not the same.

Their concentration was calculated using the Beer-Lambert law with a molar absorptivity of $300 \mathrm{~mol} \mathrm{l}^{-1} \mathrm{~cm}^{-1}$ [10]. The changes in concentration are depicted in Fig. 7.8B showing an increase of carbonyl concentration over time with the classic self-accelerating shape characteristic for the oxidation of hydrocarbon polymers.

\subsection{Double bond consumption}

On the basis of Infrared results (Fig. 7.5A and C), it is possible to distinguish three types of double bonds in the structure of PDCPD: cyclic double bond at $3049 \mathrm{~cm}^{-1}$, acyclic cis double bond at $733 \mathrm{~cm}^{-1}$ and acyclic trans double bond at $973 \mathrm{~cm}^{-1}$, which decrease with aging time. Similarly, double bonds concentration was calculated with using the Beer-Lambert equation with molar absorptivity of $19 \mathrm{~mol} \mathrm{l}^{-1} \mathrm{~cm}^{-1}$ (calculated with the help of cyclopentene) at $3049 \mathrm{~cm}^{-1}, 60 \mathrm{~mol} \mathrm{l}^{-1} \mathrm{~cm}^{-1}[11]$ at $733 \mathrm{~cm}^{-1}$, and $100 \mathrm{~mol} \mathrm{l}^{-1} \mathrm{~cm}^{-1}$ [12] at $973 \mathrm{~cm}^{-1}$.

Fig. 7.8A shows that the changes of normalized concentration of different types of double bonds, the consumption rate divided by the initial concentration of these three types 


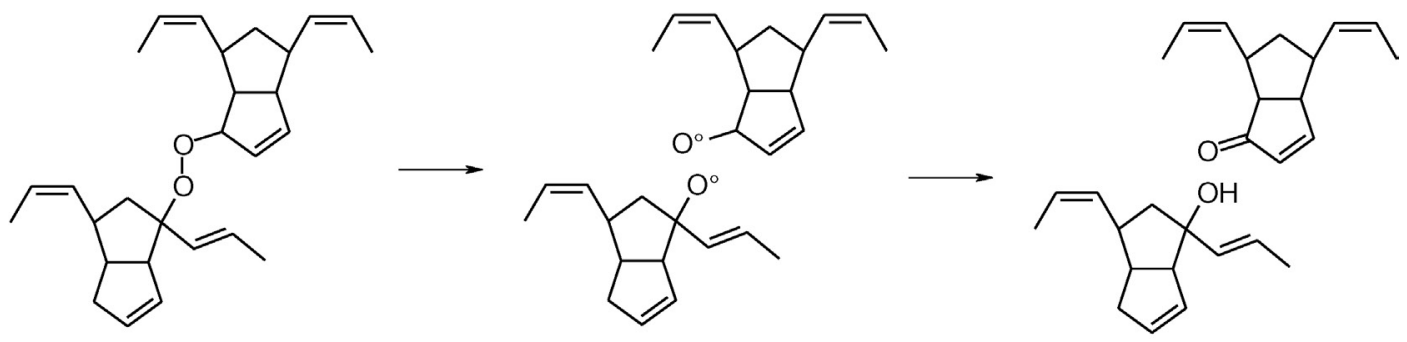

(A)

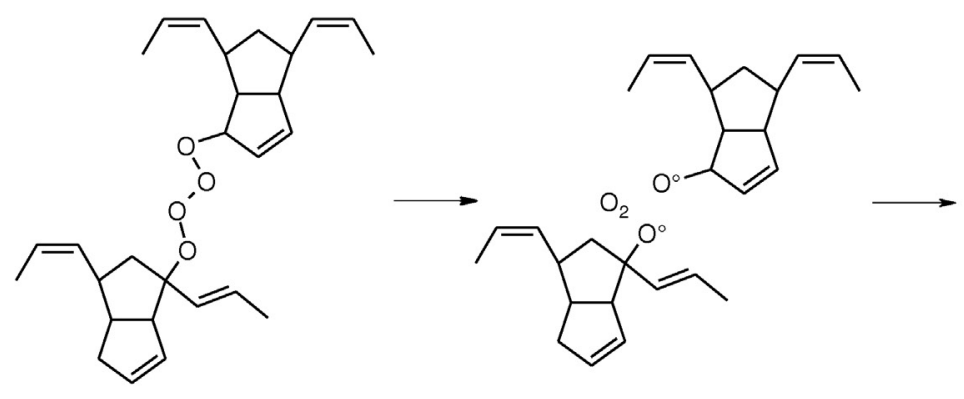

(B)

SCHEME 7.3 Formation of carbonyl from dismutation from dialkylperoxide (A) and tetroxide (B).

of double bonds are almost the same. The first hypothesis in kinetic simulation is hence that these three types of double bonds are very close (i.e., one rate constant is valid for each sort of double bonds).

According to Fig. 7.8B, the double bonds concentration decreases with aging time, certainly because of opening by alkyl of peroxyl radicals (Scheme 7.4):

\section{Kinetic modeling}

According to the above reported changes, it seems that the following mechanistic scheme might be used for modeling the kinetic curves for PDCPD:

\begin{tabular}{ll}
\hline (1u) $\mathrm{POOH} \rightarrow 2 \mathrm{P}^{\circ}+\gamma_{1} \mathrm{P}=\mathrm{O}$ & $\mathrm{k}_{1 u}$ \\
$(1 \mathrm{~b}) \mathrm{POOH}+\mathrm{POOH} \rightarrow \mathrm{P}^{\circ}+\mathrm{POO}^{\circ}+\gamma_{1} \mathrm{P}=\mathrm{O}$ & $\mathrm{k}_{1 \mathrm{~b}}$ \\
$(2) \mathrm{P}^{\circ}+\mathrm{O}_{2} \rightarrow \mathrm{POO}$ & $\mathrm{k}_{2}$ \\
$(3) \mathrm{POO}+\mathrm{PH} \rightarrow \mathrm{POOH}+\mathrm{P}^{\circ}$ & $\mathrm{k}_{3}$ \\
$(\mathrm{~A}-1) \mathrm{P}^{\circ}+\mathrm{F} \rightarrow \mathrm{x}+\mathrm{P}^{\circ}$ & $\mathrm{k}_{\mathrm{a} 1}$ \\
$(\mathrm{~A}-2) \mathrm{POO}^{\circ}+\mathrm{F} \rightarrow \gamma_{1} \mathrm{P}=\mathrm{O}+\mathrm{P}^{\circ}$ & $\mathrm{k}_{\mathrm{a} 2}$ \\
$(4) \mathrm{P}^{\circ}+\mathrm{P}^{\circ} \rightarrow \gamma_{4} \mathrm{X}+\left(1-\gamma_{4}\right) \mathrm{F}$ & $\mathrm{k}_{4}$ \\
$(5) \mathrm{P}^{\circ}+\mathrm{POO}^{\circ} \rightarrow \gamma_{5} \mathrm{POOP}+\gamma_{5} \mathrm{X}+\left(1-\gamma_{5}\right) \mathrm{F}+\left(1-\gamma_{5}\right) \mathrm{POOH}$ & $\mathrm{k}_{5}$ \\
(6) $\mathrm{POO}^{\circ}+\mathrm{POO}^{\circ} \rightarrow \mathrm{P}=\mathrm{O}+\mathrm{POH}$ & $\mathrm{k}_{6}$ \\
\hline
\end{tabular}



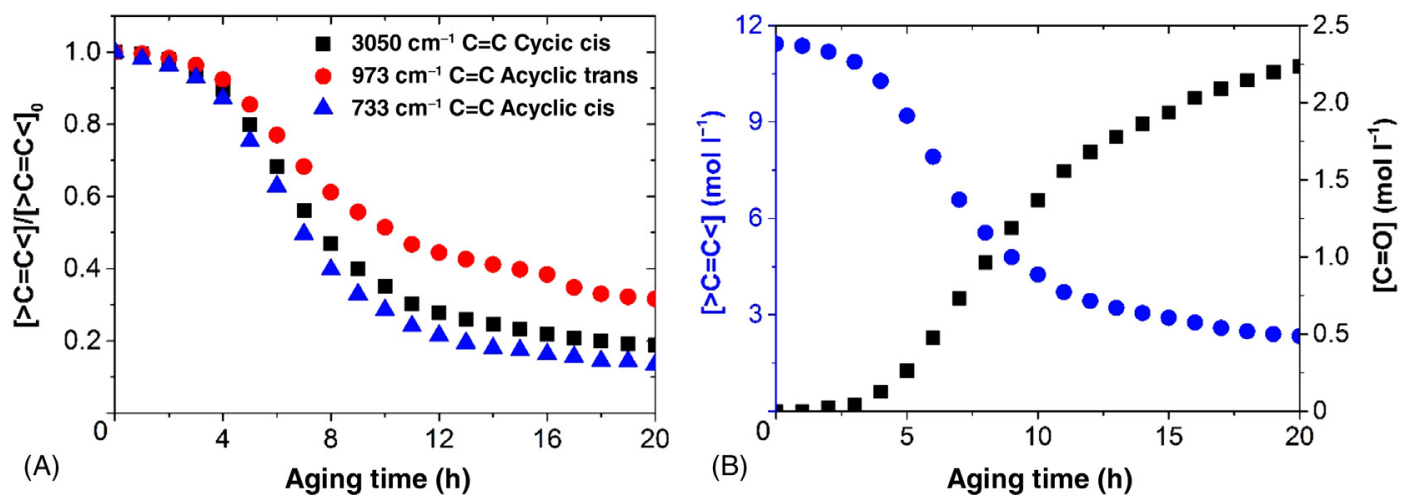

FIGURE 7.8 Concentration changes in acyclic trans double bonds at $3050 \mathrm{~cm}^{-1}$ (口), acyclic cis double bonds at $973 \mathrm{~cm}^{-1}$

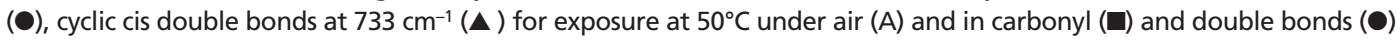
for exposure at $50^{\circ} \mathrm{C}$ under air (B).
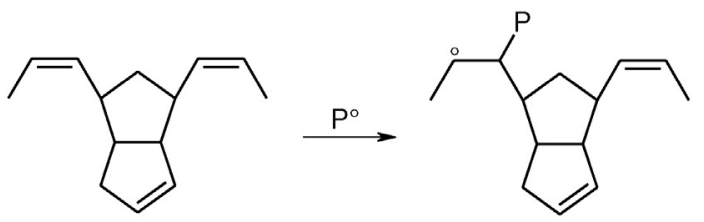

and/or

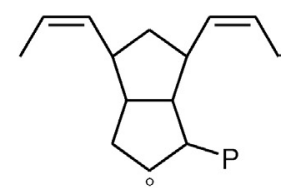

SCHEME 7.4 Possible processes of crosslinking (NB: the same can occur with POO).

where $\mathrm{POOH}, \mathrm{P}^{\circ}, \mathrm{POO}^{\circ}, \mathrm{PH}, \mathrm{F}, \mathrm{P}=\mathrm{O}$ are, respectively, hydroperoxides, alkyl, peroxy radicals, abstractable $\mathrm{C}-\mathrm{H}$, double bonds and carbonyls, $\mathrm{x}$ is crosslinking, $\mathrm{k}_{\mathrm{i}}$, and $\gamma_{\mathrm{i}}$ are, respectively, kinetic rate constants and yield for each reaction.

As published elsewhere [13] the mechanistic scheme leads to a set of differential equations. The numerical solution of this later leads to a simulation of experimental results using the following equations:

$$
\begin{gathered}
\frac{d[F]}{d t}=-k_{a 1}\left[P^{\circ}\right][F]-k_{a 2}\left[P O O^{\circ}\right][F]+\left(1-\gamma_{4}\right)\left[P^{\circ}\right]^{2}+(1-\gamma s) k_{5}\left[P^{\circ}\right]\left[P^{\circ}\right] \\
\frac{d[P=O]}{d t}=\gamma_{1} k_{1 u}[P O O H]+\gamma_{1} k_{1 b}[P O O H]^{2}+\gamma_{1} k_{a 2}\left[P O O^{\circ}\right][C=C]+k_{6}\left[P O O^{\circ}\right]^{2} \\
\frac{d[P O O H]}{d t}=-k_{1 u}[P O O H]-2 k_{1 b}[P O O H]^{2}+k_{3}\left[P O O^{\circ}\right][P H]+k_{5}\left(1-\gamma_{5}\right)\left[P^{\circ}\right]\left[P O O^{\circ}\right]
\end{gathered}
$$


The main aim is to estimate each rate constant from accelerated aging tests is to use their extrapolation to any other given exposure conditions to perform a prediction of changes in chemical structure and later the change in crosslinking from:

$$
\frac{d x}{d t}=\gamma_{4} k_{4}\left[P^{\circ}\right]^{2}+k_{a 1}\left[P^{\circ}\right][F]+\gamma_{5} k_{5}\left[P^{\circ}\right]\left[P O O^{\circ}\right]
$$

It is thus needed to propose a reliable method for estimating each involved kinetic parameter. There are schematically two options:

- Estimate the set of rate constant from best fitting approach. However, there is infinity of possible sets given the high number of parameters compared to the relative simplicity of kinetic curves for oxidation in the earliest exposure time.

- Assess independently rate constants from specific experiments, as it will be developed below.

According to several papers, the rate constants for propagation obey well-defined structure-oxidizability relationships:

- $\mathrm{k}_{2}$ is close to $10^{8} 1 \mathrm{~mol}^{-1} \mathrm{~s}^{-1}$ for hydrocarbon compounds [14]

- $\mathrm{k}_{3}$ is taken from the value of polybutadiene which is unsaturated thermoset like PDCPD [13]

It remains to estimate $\mathrm{k}_{1 \mathrm{u}}, \mathrm{k}_{1 \mathrm{~b}}, \mathrm{k}_{\mathrm{a} 1}, \mathrm{k}_{\mathrm{a} 2}, \mathrm{k}_{4}, \mathrm{k}_{5}$, and $\mathrm{k}_{6}$.

The thermolysis under vacuum of hydroperoxides previously generated during an exposure under air is described by the following equation:

$$
\frac{d[\mathrm{POOH}]}{d t}=-k_{1 u}[\mathrm{POOH}]-2 k_{1 b}[\mathrm{POOH}]^{2}
$$

However, when POOH concentration reaches the plateau in Fig. 7.6B, thermolysis data fit pretty well with a second order reaction kinetics, consistently with the relatively high concentration in $\mathrm{POOH}$ making the bimolecular decomposition much faster than first order one. The rate constant for bimolecular process $\mathrm{k}_{1 \mathrm{~b}}$ can thus be directly estimated from the slope in in Fig. 7.9.

The unimolecular process is, however, expected to play a more significant importance at low hydroperoxides concentration, i.e., in the earliest conversion degrees. Its importance is also supposed to be greater under air than under elevated oxygen pressure (since $\mathrm{POOH}$ concentration increases with external oxygen pressure) [15].

We have thus chosen the following strategy:

- The value of $\mathrm{k}_{\mathrm{lb}}$ is the slope of this bimolecular linear equation. The yield of carbonyl $\gamma_{1}$ was obtained by thermolysis of hydroperoxides (Fig. 7.10).

- $\mathrm{k}_{1 \mathrm{u}}$ is adjusted from the kinetic curves to permit a good fit under air and elevated oxygen pressure.

Let us now turn to rate constants for termination $\left(\mathrm{k}_{4}, \mathrm{k}_{5}, \mathrm{k}_{6}\right)$ and double bonds opening $\left(\mathrm{k}_{\mathrm{a} 1}, \mathrm{k}_{\mathrm{a} 2}\right)$. Under very elevated oxygen pressure, $\mathrm{P}^{\circ}$ radicals are almost instantaneously 

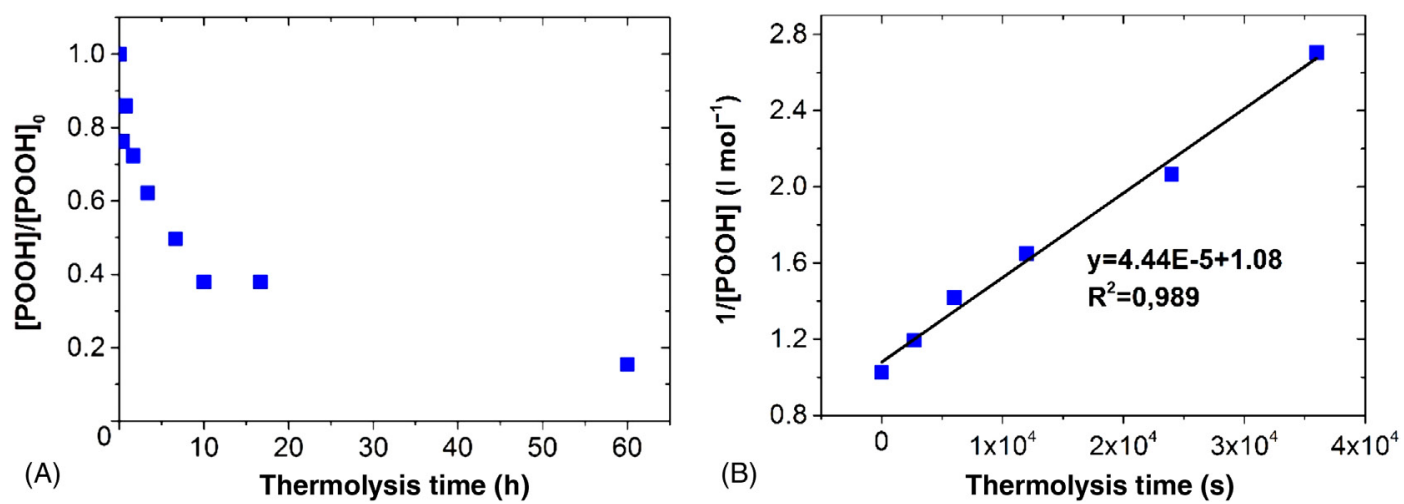

FIGURE 7.9 Thermolysis curve of hydroperoxides at $90^{\circ} \mathrm{C}$ in $\mathrm{N}_{2}$ (A). Second order plot for POOH decomposition (B).

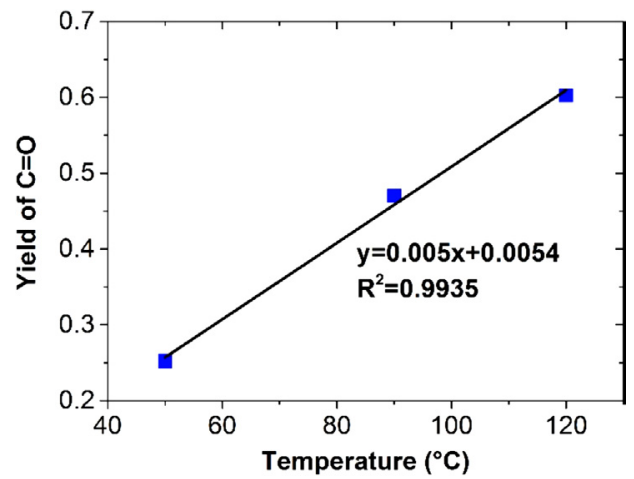

FIGURE 7.10 Carbonyl yield as a function of temperature.

scavenged so that reactions (a1), (4) and (5) are almost negligible. It can thus be shown in a first approach that:

$$
\begin{gathered}
v_{\text {ox excess }}=\frac{d[\mathrm{P}=\mathrm{O}]}{d t}=\gamma_{1 b} k_{1 b}[\mathrm{POOH}]^{2}+\gamma_{6} k_{6}\left[P O O^{\circ}\right]^{2}=\frac{\left(\gamma_{1 b}+1\right) k_{3}^{2}[P H]}{4 k_{6}} \\
v_{C=C \text { excess }}=-\frac{d[C=C]}{d t}=k_{a 2}\left[P O O^{\circ}\right][F]=\frac{k_{a 2} k_{3}[F]^{2}}{k_{6}}
\end{gathered}
$$

With these approximate calculations, $\mathrm{k}_{\mathrm{a} 2}$ and $\mathrm{k}_{6}$ were thus determined at $50^{\circ} \mathrm{C}$. Using $\mathrm{k}_{2}$ and $\mathrm{k}_{3}$ from literature, and $\mathrm{k}_{\mathrm{b}}$ from thermolysis experiments, a first simulation run was obtained (dotted line in Fig. 7.11). Then the above complete mechanistic scheme (with $\mathrm{k}_{6}$, $\mathrm{k}_{01}$, and $\mathrm{k}_{02}$ ) was used for adjusting $\mathrm{k}_{4}, \mathrm{k}_{5}, \mathrm{k}_{\mathrm{al}}$, and $\mathrm{k}_{1 \mathrm{u}}$ to fit the available experimental data under oxygen excess and under air (full line in Fig. 7.11). All the oxidation rate constants utilized for simulation runs are summarized in Table 7.1. 
The model failure to simulate the degradation at longer exposure time suggests further improvements (taking in to account of other reactive sites than allylic sites) would be needed. However, our main aim was to simulate the gradation until embrittlement which occurs at relatively lower conversion degrees.
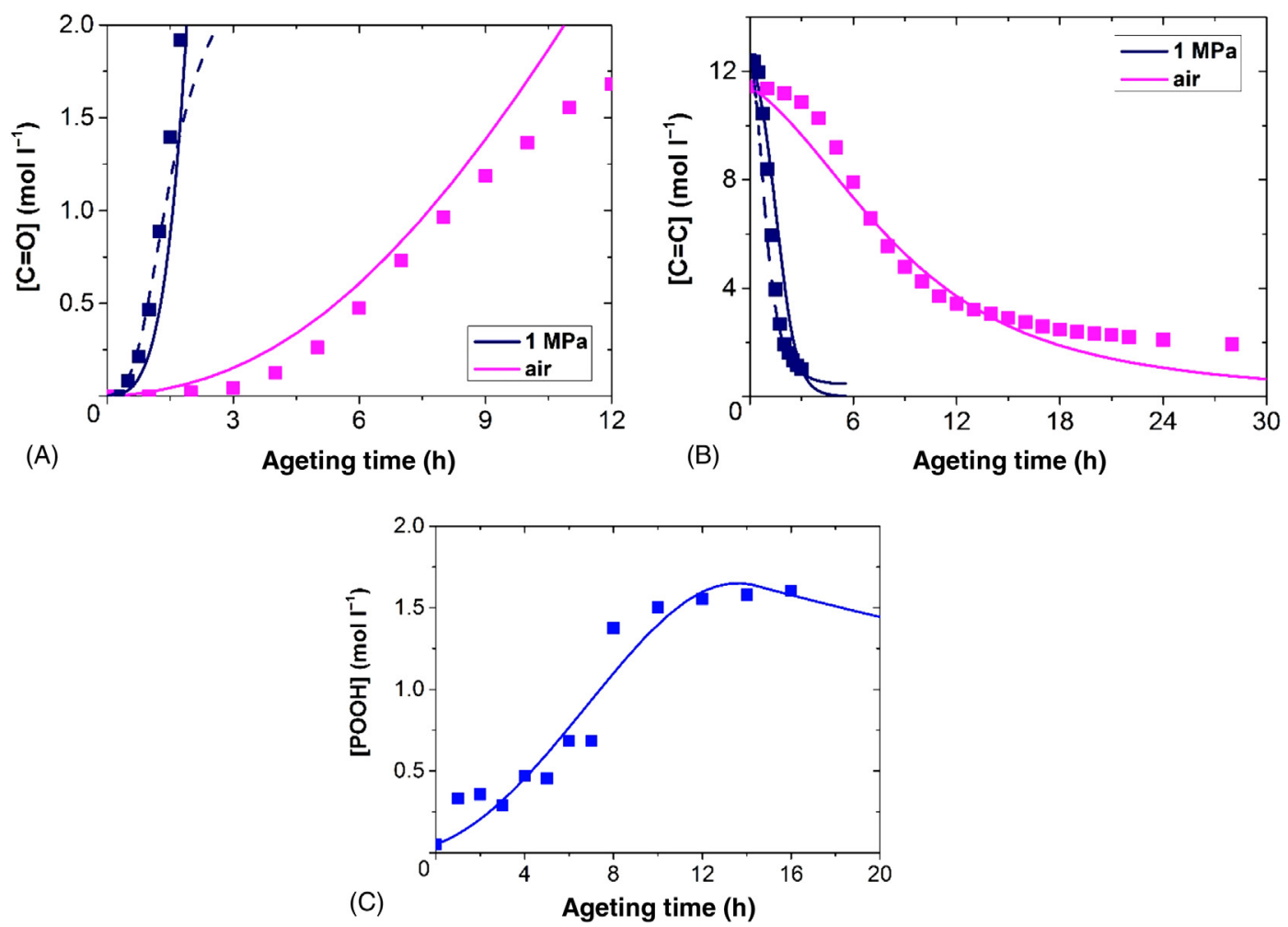

FIGURE 7.11 Simulation runs for carbonyl $(\mathrm{P}=\mathrm{O})(\mathrm{A})$ and double bonds $(\mathrm{C}=\mathrm{C})(\mathrm{B})$ and $\mathrm{POOH}(\mathrm{C})$ at $50^{\circ} \mathrm{C}$ under $1 \mathrm{MPa}$ and under air.

Table 7.1 Rate constants at $50^{\circ} \mathrm{C}$ for PDCPD, $\mathrm{k}_{1 \mathrm{u}}$ in $\mathrm{s}^{-1}, \mathrm{k}_{1 \mathrm{~b}}, \mathrm{k}_{2}, \mathrm{k}_{3}, \mathrm{k}_{\mathrm{a} 1}, \mathrm{k}_{\mathrm{a} 2}, \mathrm{k}_{4}, \mathrm{k}_{5}, \mathrm{k}_{6}$ in $1 \mathrm{~mol}^{-1} \mathrm{~s}^{-1}$.

\begin{tabular}{llllll}
\hline \multicolumn{2}{l}{ Run for dotted line } & & & \\
\hline$k_{1 \mathrm{u}}$ & $\mathrm{k}_{1 \mathrm{~b}}$ & $\mathrm{k}_{2}$ & $\mathrm{k}_{3}$ & $\mathrm{k}_{\mathrm{a} 1}$ & $\mathrm{k}_{\mathrm{a} 2}$ \\
$1.2 \times 10^{-5}$ & $1.8 \times 10^{-6}$ & $1.0 \times 10^{8}$ & 0.048 & 0 & 0.37 \\
$\mathrm{k}_{4}$ & $\mathrm{k}_{5}$ & $\mathrm{k}_{6}$ & $\gamma_{1}$ & $\gamma_{4}$ & $\gamma_{5}$ \\
0 & 0 & 10 & 0.25 & 0 & 0 \\
\hline Run for full line & & $\mathrm{k}_{2}$ & $\mathrm{k}_{3}$ & $\mathrm{k}_{\mathrm{a} 1}$ & $\mathrm{k}_{\mathrm{a} 2}$ \\
\hline $\mathrm{k}_{1 \mathrm{u}}$ & $\mathrm{k}_{1 \mathrm{~b}}$ & $1.0 \times 10^{8}$ & 0.048 & 9000 & 0.37 \\
$1.2 \times 10^{-5}$ & $1.8 \times 10^{-6}$ & $\mathrm{k}_{6}$ & $\gamma_{1}$ & $\gamma_{4}$ & $\gamma_{5}$ \\
$\mathrm{k}_{4}$ & $\mathrm{k}_{5}$ & 10 & 0.25 & 0 & 0 \\
$5.0 \times 10^{8}$ & $1.7 \times 10^{8}$ & 10 & & & 0 \\
\hline
\end{tabular}


Table 7.2 Constant rates used for modeling oxidation at $50^{\circ} \mathrm{C}$.

\begin{tabular}{llll}
\hline & Polybutadiene [13] & Polyisoprene [17] & Polychloroprene [18] \\
\hline $\mathrm{k}_{\mathrm{a} 1}\left(\mathrm{I} \mathrm{mol}{ }^{-1} \mathrm{~s}^{-1}\right)$ & 620 & $3.83 \times 10^{4}$ & 97 \\
$\mathrm{k}_{\mathrm{a} 2}\left(\mathrm{Imol} \mathrm{mo}^{-1}\right)$ & 0.01 & 7.61 & 0.16 \\
\hline
\end{tabular}

It is shown that the set of kinetic constants obtained by inverse method makes it possible to obtain a satisfying simulation of the accumulation curves of carbonyls, hydroperoxides and decrease curves of double bonds. Moreover, the magnitude orders of these rate constants follow the following classification:[16]

$$
10^{9}>\mathrm{k}_{4} \geq \mathrm{k}_{5}>\mathrm{k}_{6}
$$

which is general classification for most polymers.

The order of magnitude of $k_{a 1}$ with $k_{a 2}$ for PDCPD is observed to be in line with the case of the other rubbery polymers (see Table 7.2) where:

$$
\mathrm{k}_{a 1} \mathrm{k}_{a 2}
$$

\section{Conclusions}

This chapter presents a methodological approach for predicting the lifetime of polymers applied in the case of PDCPD submitted to thermal oxidation. It is shown this polymer undergoes thermal oxidation leading mainly to an increase in $\mathrm{T}_{\mathrm{g}}$ and yield stress and a decrease of ultimate elongation. The rate of crosslinking can be predicted from a nonempirical model in which kinetic approach describes the chemical changes induced by thermal oxidation (mainly the appearance of oxygenated species such as unstable peroxides and stable carbonyls). The proposed model can reasonably fit the experimental data presented here for aging at $50^{\circ} \mathrm{C}$. It remains now to extend those predictions in the case of bulky materials (i.e., by adding the diffusion coupling phenomena) together with adding to the mechanistic scheme the effect of commercial antioxidants to dispose of a nonempirical tool for polymers lifetime prediction.

\section{References}

[1] P.Y. Le Gac, D. Choqueuse, M. Paris, G. Recher, C. Zimmer, D. Melot, Durability of polydicyclopentadiene under high temperature, high pressure and seawater (offshore oil production conditions), Polym. Degrad. Stab. 98 (2013) 809-817, doi: 10.1016/j.polymdegradstab.2012.12.023.

[2] J.-P. Pascault, H. Sautereau, J. Verdu, R.J. Williams, Thermosetting polymers, Marcel Dekker, New York, (2002).

[3] P. Gijsman, W. Dong, A. Quintana, M. Celina, Influence of temperature and stabilization on oxygen diffusion limited oxidation profiles of polyamide 6, Polym. Degrad. Stab. 130 (2016) 83-96, doi: 10.1016/j.polymdegradstab.2016.05.024.

[4] M. Celina, J. Wise, D.K. Ottesen, K.T. Gillen, R.L. Clough, Oxidation profiles of thermally aged nitrile rubber, Polym. Degrad. Stab. 60 (1998) 493-504, doi: 10.1016/S0141-3910(97)00113-4. 
[5] V. Defauchy, P.Y. Le Gac, A. Guinault, J. Verdu, G. Recher, R. Drozdzak, E. Richaud, Kinetic analysis of polydicyclopentadiene oxidation, Polym. Degrad. Stab. 142 (2017) 169-177, doi: 10.1016/j. polymdegradstab.2017.06.005.

[6] E. Richaud, F. Farcas, B. Fayolle, L. Audouin, J. Verdu, Hydroperoxide build-up in the thermal oxidation of polypropylene - a kinetic study, Polym. Degrad. Stab. 92 (2007) 118-124, doi: 10.1016/j. polymdegradstab.2006.08.010.

[7] J.-L. Gardette, J. Lemaire, Advantages and limits of hydroperoxide titration methods in solid polymers, Polym. Photochem. 7 (1986) 409-416, doi: 10.1016/0144-2880(86)90008-4.

[8] E. Richaud, P.Y. Le Gac, J. Verdu, Thermooxidative aging of polydicyclopentadiene in glassy state, Polym. Degrad. Stab. 102 (2014) 95-104, doi: 10.1016/j.polymdegradstab.2014.01.036.

[9] G.A. Russell, The rates of oxidation of aralkyl hydrocarbons. Polar effects in free radical reactions 1, 2, J. Am. Chem. Soc. 78 (1956) 1047-1054, doi: 10.1021/ja01586a047.

[10] E. Richaud, F. Farcas, B. Fayolle, L. Audouin, J. Verdu, Hydroperoxide titration by DSC in thermally oxidized polypropylene, Polym. Test. 25 (2006) 829-838, doi: 10.1016/j.polymertesting.2006.04.010.

[11] J. Calvert, J. Pitts, Photochemistry, Wiley, New York, (1966).

[12] H.L. McMurry, V. Thornton, Correlation of infrared spectra, Anal. Chem. 24 (1952) 318-334, doi: $10.1021 / \mathrm{ac} 60062 \mathrm{a} 018$.

[13] M. Coquillat, J. Verdu, X. Colin, L. Audouin, R. Nevière, Thermal oxidation of polybutadiene. Part 2: Mechanistic and kinetic schemes for additive-free non-crosslinked polybutadiene, Polym. Degrad. Stab. 92 (2007) 1334-1342, doi: 10.1016/j.polymdegradstab.2007.03.019.

[14] E.T. Denisov, I.B. Afanas'ev, Oxidation and Antioxidants in Organic Chemistry and Biology, Taylor \& Francis, Boca Raton, (2005).

[15] E. Richaud, F. Farcas, P. Bartoloméo, B. Fayolle, L. Audouin, J. Verdu, Effect of oxygen pressure on the oxidation kinetics of unstabilised polypropylene, Polym. Degrad. Stab. 91 (2006) 398-405, doi: 10.1016/j.polymdegradstab.2005.04.043.

[16] K.T. Gillen, J. Wise, R.L. Clough, General solution for the basic autoxidation scheme, Polym. Degrad. Stab. 47 (1995) 149-161, doi: 10.1016/0141-3910(94)00105-H.

[17] X. Colin, L. Audouin, J. Verdu, Kinetic modelling of the thermal oxidation of polyisoprene elastomers. Part 1: Unvulcanized unstabilized polyisoprene, Polym. Degrad. Stab. 92 (2007) 886-897, doi: 10.1016/j.polymdegradstab.2007.01.017.

[18] P.Y. Le Gac, G. Roux, J. Verdu, P. Davies, B. Fayolle, Oxidation of unvulcanized, unstabilized polychloroprene: a kinetic study, Polym. Degrad. Stab. 109 (2014) 175-183, doi: 10.1016/j. polymdegradstab.2014.06.019. 